\title{
Sedução e Descaminho - Narrativas e Identidades de Jovens em Situação de Rua
}

\author{
Seduction and Deviation - Street Youth's Narratives and Identities
}

\author{
Hugo Juliano Duarte Matias* \\ Universidade de Brasília, Brasília, Distrito Federal, Brasil
}

\begin{abstract}
Resumo
Trata-se do estudo de narrativas produzidas por jovens durante pesquisa etnográfica, realizada em Natal/RN, com grupo de pessoas em situação de rua, cujo objetivo foi investigar processos de construção de identidade. Duas narrativas, obtidas em entrevistas, foram analisadas em seus aspectos retórico-formais e submetidas à análise de posicionamento. As análises revelam complexidade retórica e climas afetivos e morais diversificados. As identidades foram construídas pelos jovens em estreita dependência da avaliação de seu próprio papel na produção das circunstâncias atuais de suas vidas. A saída da casa à rua foi apresentada como ruptura biográfica em suas narrativas, e nelas destacam-se sua forte ligação ao discurso social sobre casa e rua, não obstante a singularidade das identidades que revelam.

Palavras-chave: Jovens em situação de rua, identidade, narrativa, self.
\end{abstract}

\begin{abstract}
This is a study of narratives produced by young people during an ethnographic research conducted in Natal-RN with homeless youths aiming to investigate identity construction processes. Two narratives obtained from interviews were analyzed in their formal-rhetorical aspects and submitted to positioning analysis. Such analyses revealed rhetorical complexity and diversity in their emotional and moral climates. The identities were built by youngsters in close dependence to the evaluation of their own role in the production of their current life circumstances. Leaving their homes to go to the streets was presented as a break in their biographical narratives, which were highlighted by their strong ties to social discourse about home and street, despite the uniqueness of the identities they reveal.

Keywords: Street youth, identity, narrative, self.
\end{abstract}

João do Rio (1908/2008) escreveu sobre o medo e o susto com que os pais falavam aos seus filhos sobre a rua. Suas palavras, muito eloquentemente, apontam o fato de que as pessoas temiam os efeitos de sedução que a rua exercia, embora difusamente discernidos. E ainda hoje, tanto ou mais, esta preocupação concerne crianças e jovens - principalmente os mais pobres - em sua vulnerabilidade à ação de "captura de subjetividade" da rua. Quanto mais isto é percebido, mais as atenções se voltam para os processos de construção das formações identitárias das crianças e jovens em situação de rua.

De fato, nos últimos anos, o problema das formações identitárias desses grupos tem sido valorizado e largamente investigado. Vogel e Mello (1996), por exemplo, dão muita importância ao estudo da identidade para o entendimento

" Endereço para correspondência: Rua Maria Buri dos Santos, 370 - Chapadinha - Cruz das Almas/BA - CEP 44380-000. E-mail: hugo_jdm@yahoo.com.br

$\mathrm{O}$ autor agradece: à Coordenação de Aperfeiçoamento de Pessoal de Nível Superior (CAPES), pela bolsa de pesquisa; à professora Dra. Rosângela Francischini pelo diálogo generoso e paciente durante o processo de realização da pesquisa de que esse relato é parte. da experiência da rua. Outros pesquisadores tomam a rua como espaço simbólico de socialização (Matias \& Francischini, 2010a) que localiza um complexo sistema identitário (Gregori, 2000; Invernizzi, 2003; Lucchini, 2001). Estudos empíricos demonstram que a representação de pessoas em situação de rua é negativa, em particular, crianças e jovens (Alvim, 2001; Mattos \& Ferreira, 2004). Além disso, percebe-se que a rua é associada a sentidos negativos por aquelas crianças e jovens que não estão na rua (Guareschi et al., 2002) e pelas que estão (Raffaelli et al., 2001; Ribeiro, 2003).

Essa imagem negativa faz parte dos sistemas de identificação disponíveis às crianças e jovens em situação de rua (Rosa, 1999). Isso sob efeito de processos de socialização em que se inserem (Trussell, 1999) e processos sociais mais amplos (Hodgetts, Hodgetts, \& Radley, 2006). Uma evidência empírica da realidade desses sistemas de identificação e de sua ação coercitiva é o esforço que essas crianças e jovens fazem para se manter em relação de exterioridade ou alteridade com o estigma da rua. Em seu discurso, se defendem da ação corrosiva do estigma tentando fazer crer que não pertencem à rua. Essa é uma forma de proteger a representação que têm de si (Alves- 
-Mazzotti, 1997; Nóbrega \& Lucena, 2004), tentando resguardar sua identidade.

Essa posição defensiva e indisposta a rótulos é legítima já que essas crianças e jovens não constituem categoria social homogênea, inclusive no plano psicossociológico. Além disso, suas histórias se traduzem muito diversamente quanto às formações identitárias, formas de inserção num espaço ou grupo e suas competências (Lucchini, 2001).

$\mathrm{O}$ estudo da identidade, portanto, pode fornecer um referencial muito útil para a compreensão das condições de existência daqueles que se encontram nas ruas. Assim, o objetivo deste trabalho é investigar processos de construção de identidade em que os jovens em situação de rua interpretam os signos de seu próprio contexto sócio-histórico, com cuja interpretação dão significado à realidade.

$\mathrm{Na}$ abordagem aqui pretendida, a identidade se constrói dentro de relações sociais, isto é, a construção das formas identitárias se instala no interior dos processos de subjetivação e estes processos, por sua vez, ocorrem nas mais diversas modalidades de interação social. Isso implica uma dualidade fundamental, o caráter relacional e subjetivo tanto do social como psíquico. O fulcro dessa perspectiva é o construcionismo de Mead (1934/1972) e sua teoria da subjetividade.

Em seu interesse filosófico pela questão do fundamento epistêmico de todo discurso sobre o self, Mead (1934/1972) investigou a dualidade que lhe é própria. No processo de autorreferência reflexiva, o self é objeto e sujeito do pensamento. Isso se explica pelo fato de que a reflexão ocorre no interior de processos de interação social humana, um espaço de mediação simbólica. É pelo recurso à linguagem que alguém pode se experimentar como outro de si mesmo, tomando-se como objeto para coordenar a própria ação à de outros.

É a linguagem que torna possível o vínculo da consciência ao espaço intersubjetivo. Primeiro, a ação de alguém é problematizada em seus efeitos sociais na linguagem do outro; então, a mesma linguagem serve a cada um para a objetivação da própria ação e para a problematização da própria consciência, suposta origem dessa ação. Aí está a possibilidade de autocompreensão do self. A experiência de alguém como self é, portanto, recíproca. O social self de Mead (1934/1972) consiste no fato de que alguém produz sentido sobre si com as coordenadas oferecidas pela interpretação de outrem acerca de sua própria ação.

Habermas (1990) sugere que uma das consequências dessa teoria é que na medida em que a autorreferência e a autorrelação são deslocadas do sujeito para a situação comunicativa, a subjetividade se revela em suas feições de intersubjetividade e mostra a sua dependência da ação, ou seja, a interação é mediada simbolicamente. Portanto, há dependência constante dos processos de subjetivação à linguagem e à ação comunicativa. Outra consequência dessa teoria, notada por Ezzy (1998), é que insere necessariamente o tema da construção da subjetividade na discus- são sobre a dimensão temporal da experiência subjetiva. Ora, se o sujeito visita a ação já ocorrida e objetivada para compreender a si mesmo no presente e planejar o futuro como propõe Mead (1934/1972) -, isso faria da produção ininterrupta da autorreferência um constante esforço de integração do tempo vivido.

Disso se recortam dois enquadres analíticos essenciais no estudo das formas identitárias: (a) identidade como um fenômeno local e contextual; (b) a narrativa da história de vida como forma de representação identitária fundamental. O primeiro deles implica conceber a identidade como significação temporária, algo que emerge sob os modos mais diversos de condensar categorias sociais e a experiência pessoal de uma predicação de si. Essas formas identitárias são mais voláteis, produzidas no instante mesmo da conversação e da ação comunicativa. Segundo Bruner (1997), "o si-mesmo, nesta situação, torna-se 'dependente de um diálogo', projetado tanto para o receptor de nosso discurso como para propósitos intrapsíquicos" (p. 90). Portanto, a identidade constitui-se como posição assumida no ato de engajar-se em uma situação discursiva. As formas identitárias, no entanto, se dispersam entre as múltiplas exigências discursivas e, no próprio discurso, ganham realidade em contornos lexicais, gramaticais, prosódicos, na dinâmica de colaboração discursiva, e acabam se constituindo em formas múltiplas e parciais (Ochs \& Capps, 1996).

A despeito da dinamicidade das formas identitárias, $o$ discurso produzido no interior das situações de comunicação é eventualmente fixado sob organização específica, a saber, em sua forma mais rica, a identidade como discurso narrativo. Bruner (1998) sugere que a importância da narrativa está em sustentar a ligação entre o sentido do si-mesmo e dos outros no mundo social, e também no fato de que talvez a narrativa seja a única forma pela qual se pode descrever o "tempo vivido", por causa de sua relação mimética com a vida.

A narrativa que estrutura a representação da vida é estruturada segundo modelos oferecidos pela cultura em repertórios limitados. A afinidade entre a forma narrativa e self desempenha papel privilegiado nos processos de construção da identidade (Bruner, 1996). A narrativa nasce da experiência e lhe dá forma (Ochs \& Capps, 1996), medeia o envolvimento do self e o mundo, e agencia os sentidos de ambos. A assunção da identidade na narrativa sustenta a mesma e fundamental relação entre a realidade social e subjetiva, o que pode ser notado nos relatos que estudam narrativas como fontes privilegiadas de informação sobre a identidade entre jovens em situação de rua (Brunanski, 2008; Butler, 2009; Cruz \& Assunção, 2008; Grundling \& Grundling, 2005; Haldenby, Berman, \& Forchuk, 2007; Mathur, 2009).

Assim, a possibilidade representacional que a narrativa oferece às formas identitárias completa o enquadre conceitual para a identidade que constitui a abordagem deste estudo. O objetivo mais específico, portanto, é investigar processos de construção de identidade em narrativas de história de vida dos jovens em situação de rua. 
Matias, H. J. D. (2013). Sedução e Descaminho - Narrativas e Identidades de Jovens em Situação de Rua.

\section{Método}

\section{Participantes}

Este trabalho é parte de um estudo mais amplo (Matias, 2008), em que se realizou pesquisa etnográfica com um grupo de 11 pessoas em situação de rua -8 homens e 3 mulheres, predominantemente jovens (entre 16 e 18 anos) - na cidade de Natal/RN. As opções metodológicas e os detalhes deste estudo foram discutidos em (Matias \& Francischini, 2010b), e ainda, as diversas formas pelas quais o tema da identidade foi abordado foram discutidas em (Matias, 2011).

\section{Procedimentos}

Trata-se aqui da análise das narrativas de história de vida produzidas pelos participantes durante a pesquisa. Dos 11 participantes, 6 aceitaram o convite para produzir estas narrativas. Não podendo ser representada, de modo breve, toda a variedade de composições singulares, duas narrativas foram escolhidas para apresentar essa diversidade.

Os critérios segundo os quais o texto das narrativas foi delimitado para a extração do contexto da entrevista, bem como as orientações para sua disposição e notação (conforme apresentação em seguida), correspondem a um modelo adaptado de Labov (1997) para análise de narrativas orais de experiência pessoal. Segundo esse modelo, a narrativa é delimitada por fórmulas de introdução e encerramento. Mesmo quando essas fórmulas não estão presentes, os limites da narrativa podem ser inferidos semanticamente do próprio texto e seu contexto. A narrativa é vista, para efeito de análise, como um conjunto de cláusulas entre as quais são essenciais cláusulas narrativas, cujo relato se reconstrói e transmite uma experiência e cuja relação produz a conjuntura temporal da narrativa. Todas as cláusulas se distinguem por suas características funcionais e estruturais. Segundo essa tipologia, as cláusulas narrativas são de orientação (apresentam personagens, tema e referências espaço-temporais), complicação (eventos e ação), avaliação (apreciação de personagens, ações, eventos e do mundo da narrativa), resolução (desfecho e consequências) e coda (informam o final da narrativa).

A avaliação ocorre sob três formas: (a) externa: o narrador interrompe a narrativa para comunicar um ponto de vista; (b) intrínseca: elementos de avaliação se introduzem subrepticiamente em cláusulas de outro tipo, como léxico, formas sintáticas específicas, etc.; (c) ação avaliativa: a própria ação relatada produz efeitos apreciativos (Labov, 1972).

No sistema de transcrição adotado, (...) corresponde às menores pausas entre as frases, (/) corresponde a uma interrupção abrupta, (::) corresponde ao prolongamento do som da sílaba imediatamente anterior, (?) corresponde à entonação interrogativa, sublinhado corresponde à ênfase prosódica, e os números entre parênteses correspondem ao tempo que durou cada pausa tão longa quanto um segundo ou mais, em segundos e suas frações.
Depois de organizadas, as narrativas foram submetidas a uma análise retórico-formal, isto é, uma análise dos recursos retóricos utilizados para a composição narrativa na criação de seu clima afetivo e moral: figuras usadas, léxico, tempos verbais, assim como a eficácia desses recursos na produção de argumentos em auxílio à teoria causal implícita na narrativa. Ora, segundo o teorema laboviano (Labov, 1997), o tipo de construção narrativa aqui discutida requer uma teoria pessoal de causalidade que explique, justifique ou dê plausibilidade à ocorrência de um evento crítico $\left|\mathrm{e}_{0}\right|$. Essa teoria é constituída pela apresentação de outros eventos como causa $\left(\left|\mathrm{e}_{-\mathrm{n}}\right| \ldots\left|\mathrm{e}_{-1}\right| \rightarrow\left|\mathrm{e}_{0}\right|\right)$. Desse modo, cada um dos narradores apresentará uma teoria explicativa para aquilo que é crítico em sua história de vida.

Como já sugerido, o ato de produzir uma narrativa é simultâneo ao posicionamento do self diante do mundo semanticamente construído no discurso e na interação, principalmente se a narrativa pretende a transmissão de experiência pessoal. $O$ último tipo de análise a que essas narrativas foram submetidas consiste na análise de posicionamento (Bamberg, 2004; Bamberg \& Georgakopoulou, 2008). São valorizados os processos de negociação de sentido, isto é, pelo mapeamento das categorias sociais negociadas na interação mediada simbolicamente, na refiguração desses sentidos dispersos pelo ato de sua interpretação. Isso visa às formas identitárias em nível microscópico, onde são acessadas. Desse modo, se orienta segundo princípios da análise dos processos comunicacionais numa abordagem sociocultural. Tais processos são sumarizados por Bucholtz e Hall (2005) desde a linguística sociocultural.

É preciso salientar que, muito embora Bamberg e Georgakopoulou (2008) enfatizem a ligação desse tipo de análise com a investigação do que eles chamam de small stories, os dados aqui tratados estão situados entre as pequenas histórias e os relatos orais curtos de experiências pessoais, extensamente investigados pelo recurso ao modelo laboviano. Em suas narrativas, cada um dos jovens narrou como chegou à rua e as razões ou circunstâncias que os fizeram ficar na rua. Essas narrativas foram desencadeadas pelo acordo a que chegaram esses jovens e o pesquisador, quando da negociação sobre a orientação que tomaria a pesquisa. Sumariamente, o acordo foi que os meninos e meninas contariam as suas histórias para que fossem recontadas pelo pesquisador em outros lugares, fora da rua (Matias \& Francischini, 2010b). Além disso, as narrativas assumiram a configuração na qual são apresentadas também em função dos limites impostos pelo estilo de vida e as estratégias de sobrevivência dos jovens em situação de rua, isto é, pelas concessões que isso lhes permite fazer em uma entrevista com um pesquisador (Matias \& Francischini, 2010b). Portanto, não são autobiografias escritas ou contadas pelos meninos, mas o que Georgakopoulou (2006) chama narrativas-em-interação. Isso, em função de seu caráter de pequenos relatos que pretendem transmitir experiência pessoal, sob forma falada, mais próxima das situações dialógicas em que as formas 
identitárias são construídas discursivamente no espaço das práticas cotidianas desses jovens. Mesmo assim, foram obtidas em entrevistas eliciadas pelo pesquisador, em que ele assumia postura passiva-minimalista (conforme Jones, 2003), o que implica um procedimento não-estruturado e minimamente diretivo. No entanto, isso não descaracteriza a situação como de interação, mas apenas lhe confere uma dimensão econômica particular. E muito tem a ver com o próprio contexto de sua produção, no ambiente da rua, na presença de muitas pessoas, numa conversa informal e sem a mesma proteção institucional em que é produzida a maior parte dos relatos de história de vida.

Segundo Bamberg (2004),

o ponto de vista da narrativa a partir do qual os seus personagens [dimensão objetivada do self e os "outros"] são ordenados no mundo da narrativa deixa escapar ... o ponto de vista de onde aquele que fala ["eu"] representa a si mesmo. (p. 223)

É fundamental, portanto, a atenção à organização imposta ao mundo referencial da narrativa, sob a suposição de que é função do engajamento interativo e aponta para o modo como o "eu" quer ser entendido (Bamberg, 2008; Bamberg \& Georgakopoulou, 2008).

A análise de posicionamento se realiza em três níveis (Bamberg \& Georgakopoulou, 2008). No nível 1, análise do modo como os personagens são posicionados na história uns em relação aos outros e no tempo e espaço (refere-se ao mundo da narrativa). No nível 2 , análise de como o protagonista/narrador se posiciona na situação interativa em que constrói sua narrativa (refere-se ao aqui e agora do narrador enquanto narra). Com o fim de sumarizar essa análise, os diferentes posicionamentos levantados estão descritos em seis caracteres. Estes foram produzidos para a análise das narrativas aqui estudadas, na situação interativa em que foram compostas. Eles são: (a) self-autor - integra a narrativa e dispõe seus elementos sob o efeito de compromissos variados, sendo o que "assina" a narração e sua teoria implícita; (b) self-ator - apresentado como personagem da narração; (c) self-interessado - representa os interesses subjacentes à apresentação da teoria narrativa à audiência; (d) anti-self-produto da antecipação do autor sobre as suposições da audiência acerca de seu personagem; (e) mundo - conjunto dos outros elementos da narrativa, como tempo, espaço, recursos, antagonistas, etc.; (f) outro - corresponde à audiência no modo como é produzida discursivamente pela narrativa, em função de seus objetivos, suposições, concessões, etc. A investigação desses caracteres completa a análise retórico-formal. No nível 3, a análise de como o protagonista/narrador produz sentido sobre si e suas condições de existência posicionando-se em referência ao discurso social. Neste caso, o discurso-mestre, ou seja, o discurso social dominante para este tema (primordial/norteador), refere-se à oposição entre casa e rua (ver Matias, 2008, 2011).

Por fim, esta pesquisa foi submetida e aprovada junto a um comitê de ética competente para isso (CAAE, 0014.0.051.000-07).

\section{Resultados e Discussão}

Narrativa 1 - (N1) - menino, 17 anos:

[Orientação] meu nome é Y... tenho dezessete anos... sou do noventa e.: eu vivo no mundo das drogas... no meio da rua... [Complicação] aos meus:: seis anos eu sai de casa $\left|\mathrm{e}_{-5}\right| \ldots$ fui para a rua conhecer:: é:: um outro mundo... aos sete anos foil ponhei minha primeira garrafa de cola na boca $\left|\mathrm{e}_{-4}\right|$... aos oito já fui para um instituto de criança de menor $\left|\mathrm{e}_{-3}\right| \ldots$ a Casa Lar Santa Catarina II... aos doze anos eu sai de lá e:: como eu sai de lá eu fui para a casa da minha mãe $\left|\mathrm{e}_{-2}\right|$... retornei para lá... e eu já tava intoxicado com a cola... e.: esse: tempo todinho que eu passei lá fugia... ia pra rua... retornava de novo... só ia pra lá pra tomar um banho... trocar de roupa... e voltava pra rua de novo... fui pra casa da minha mãe... voltei (2.4) é:: pra rua $\left|\mathrm{e}_{-1}\right| \ldots$ e fiquei $\left|e_{0}\right| \ldots$ [Resolução] e conheci a maconha $\left|\mathbf{e}_{1}\right|$ depois o crack $\left|\mathbf{e}_{2}\right|$... limpo para-brisa de carro $\left|\mathrm{e}_{3}\right| .$. e aqui estou né? [Avaliação] já estudei... fiz até: a quinta série e (1.9) e o que eu penso da minha vida é:: ter um trabalho me/ um trabalho melhor do que limpar para-brisa de carro... (1.4) não mendigar o pão e ter meu tra/ meu trabalho fixo... tenho/ já tive uma mulher de vinte e um ano e tenho uma filha de um ano e dois meses (3.0) e eu pretendo:: sair da rua... mas: eu acho que:: o tóxico é que não deixa sabe? e só o que pode me libertar mesmo é o Senhor Jesus... e um apoio muito grande que eu:: queria ter... mas até agora ainda não encontrei essa oportunidade... é só isso mesmo que eu tenho dizer... [Coda] é só isso mesmo que eu tenho dizer...

Narrativa 2 - (N2) - menina, 16 anos:

[Complicação] minha mãe me deu $\left|\mathrm{e}_{-7}\right|$ com quatro ano de idade a uma mulher... sabe? lá no... no Gramoré... só que o filho dela era muito ruim pra mim... ai minha mãe foi buscar eu lá $\left|\mathrm{e}_{-6}\right|$ (1.3) lá da casa dela... sabe? ai trouxe eu pra cá $\left|\mathrm{e}_{-5}\right| \ldots$ ai depois eu/minha mãe ficou com (1.1) com meu padrasto $\left|\mathrm{e}_{-4}\right|$... ai ela me deu com quatro ano de idade a essa mulher (1.2) ai ela foi... foi pegar eu lá... eu tinha treze ano de idade quando ela pegou eu de volta pra/ pros Guarapes... aí chegou ai nos Guarapes... ai depois ela me abandonou $\left|\mathrm{e}_{-3}\right| .$. sabe? (1.1) ficava me expulsando de casa com ciúme do meu padrasto... ai expulsou eu $\left|\mathrm{e}_{-2}\right|(1.0)$ ai eu ficava na casa de um... na casa de outro... na casa de um... na casa de outro... ai era humilhada na casa de um... na casa de outro... ai eu peguei... vim pra Candelária $\left|\mathrm{e}_{-1}\right|(1.4)$ aífiquei $\left|\mathrm{e}_{0}\right| \ldots$ [Resolução/Avaliação] fazendo programa... me prostituindo $\left|\mathrm{e}_{1}\right|$...

\section{Análise de Posicionamento: Nivel 1}

$\mathrm{Em}(\mathrm{N} 1)$, o protagonista/narrador situa o marco inicial da narrativa em sua própria situação presente e daí parte para o que seria o começo de sua história, o que produz, para a narrativa, os contornos de uma digressão. Essa di- 
Matias, H. J. D. (2013). Sedução e Descaminho - Narrativas e Identidades de Jovens em Situação de Rua.

gressão, no entanto, não alcança o tempo e espaço da casa antes de sua primeira partida para a rua, de modo que esse tempo e espaço não parecem ter importância para explicar os eventos posteriores. O espaço da casa é construído apenas como um referencial suposto para o "outro mundo" que é a rua, onde todos os eventos ocorrem. Quando, por fim, o espaço da casa é mencionado, lugar de retorno, ele já não tem como que jurisdição nenhuma na narrativa: foi incapaz de guardar e é incapaz de salvar.

Do mesmo modo, não há outros personagens na narrativa que, de fato, realizem ações (este é o caso da mãe, da mulher e da filha), senão o "tóxico" - que não deixa sair da rua - e o "Senhor Jesus" - que pode libertar. Estes dois últimos personagens não podem ser qualificados propriamente como antagonistas e agonistas. Eles funcionam, na verdade, como referenciais de sua presumida falta de autodeterminação, resultado de ações anteriores.

Em (N2), o espaço da rua é aquele a que a narrativa chega, seu desfecho, papel muito diverso daquele que ocupava a rua em (N1). Não obstante a oposição à rua, o espaço da casa não assume contornos nítidos. Trata-se, antes, de um ambiente precário. $\mathrm{O}$ deslocamento é bem mais importante. Esse ambiente, na verdade, somente ganha alguma consistência no momento em que a protagonista/ narradora rompe com ele. Quanto ao tempo, a narrativa começa justamente no momento em que inicia a precarização do espaço da casa. A abordagem da protagonista/ narradora é direta e sem rodeios.

Ao contrário da (N1), na segunda narrativa há diversos outros personagens que agem sobre a protagonista. Por sua vez, o momento em que ela primeiramente age de maneira autodeterminada é aquele de sua saída definitiva para a rua. Até então ela está nas mãos de seus antagonistas, os quais, com muita clareza, desempenham esta função.

O posicionamento em cada uma das narrativas é bem diverso, aliás, claramente contrastante. Em (N1), quase todas as ações narradas ocorrem na rua, e o espaço da casa é aquele de que o protagonista/narrador vai paulatinamente se afastando. Já em (N2), quase todas as ações narradas ocorrem supostamente no espaço doméstico, até que o seu desenlace leva à rua. Mais uma vez, em (N1), a ação do protagonista/narrador é quase sempre, e desde o início, autodeterminada, até um ponto em que, aparentemente, deixa de ser autodeterminada e passa a ser dependente de outros agentes. Por outro lado, em (N2), outros agentes intervêm orientando o destino da protagonista/narradora. No último momento, sua ação é finalmente autodeterminada, no entanto, apenas quando ela parece estar sem opções.

\section{Análise das Características Retórico-Estilísticas}

Em (N1), a singularidade do $\left|e_{0}\right|$ é definida em sua natureza de equívoco, falha ou falta (cerne da teoria). Essa falta se mostra no fato de que as escolhas é que explicam os eventos e precedem as consequências indesejadas, assim como a situação em que é o próprio protagonista/ narrador o sujeito dessas escolhas, das ações na sequência narrativa. Além disso, o conteúdo valorativo negativizante das cláusulas avaliativas produz sobre o relato um clima moral de culpa e vergonha. Com respeito a isso, é possível aduzir que a situação atual do protagonista/narrador é vista como indigna ("mendigar o pão"). Também, nos momentos em que se indica na narrativa a saída para a rua, certa hesitação sugere carga emocional ("e:: eu vivo no mundo das drogas", "fui para a rua conhecer::é:: um outro mundo..."). Por fim, há um paralelo entre a passagem paulatina para a rua e a figura da "intoxicação".

Ao longo da narrativa, sua organização retórica manifesta aos poucos a hipótese do enredamento. A narrativa se constrói sobre insinuações de escolhas que, aos poucos, entram em tensão com as circunstâncias produzidas, de tal maneira que estas circunstâncias ganham autonomia e domínio sobre a ação. Desde então, mesmo o narrador vacila em sustentar suas escolhas, querendo ocultá-las. Ao fim do relato, ele se apresenta completamente assujeitado às circunstâncias e coloca-se na dependência de outro ("o Senhor Jesus", por exemplo) para desatar-se desse poder exercido sobre ele. Tal ambiguidade entre o papel das escolhas e das circunstâncias é compatível com a ideia de culpa e de seu obscurecimento pela vergonha.

O modo como a ida para a rua é tematizada faz desse evento o final do deslocamento irregular, mas progressivo, do protagonista. Tal ideia é sugerida pela importância que tem a gradação como figura. Há pelo menos duas, que intensificam o afeto e argumento do relato: (a) a primeira conduz o protagonista do primeiro contato com "um outro mundo", quando tinha seis anos, ao primeiro contato com drogas, quando tinha sete, até o momento em que ele já estava intoxicado; (b) na segunda gradação, desde o momento em que foi para rua, então "conheceu a maconha, depois o crack, limpa para-brisas de carros e está onde está". As duas gradações podem ser interpretadas como dividindo em dois momentos a narrativa: o enredamento do protagonista e seu descaminho.

Outra figura é a antítese, produzida pelo relato das idas e vindas do narrador. Seu efeito é sugerir a ambivalência entre casa e rua. Isso é amplificado pela abertura de um segundo plano temporal na narrativa: o uso dos verbos no pretérito imperfeito ("fugia... ia pra rua... retornava...") isola e prolonga o tempo de desligamento, conferindo-lhe mais dramaticidade. Aí também se iniciaria, talvez, outra gradação, pela qual o narrador sugere o afastamento progressivo de casa em direção à rua ("só ia em casa para tomar um banho... trocar de roupa...”). Assim, o desligamento de casa vai sendo construído com uma insinuação sobre a gradual falta de importância da casa. É preciso lembrar que essa janela temporal foi aberta com a seguinte declaração: "e eu já tava intoxicado com a cola...". Isso sugere como eventos posteriores mantêm relação causal com essa avaliação.

Por fim, duas outras figuras são utilizadas: o pão como símbolo da sobrevivência é evocado para produzir uma imagem de necessidade e dureza da situação de rua. Ao 
que parece, a possibilidade reivindicada de superação dessa circunstância é tal que o narrador somente dela participa como alguém a ser ajudado por outrem, já que não tem recursos. $\mathrm{O}$ outro expediente usado para composição estilística do relato é o verbo conhecer. Quando diz "fui para a rua conhecer:: é:: um outro mundo...", ou "conheci a maconha... depois o crack...", esse verbo permite associações que sugerem apropriação, descoberta e sedução.

Em (N2), o desembaraço da protagonista/narradora em sua narrativa pode ser interpretado pela perspectiva de seu compromisso com a audiência, mas também como um índice de sua clareza quanto à teoria que pretende defender. Ela apresenta uma série causal composta por eventos significativos e nexos explícitos, é assertiva, de modo que a teoria explicativa que leva ao $\left|\mathrm{e}_{0}\right|$ é coesa e clara. Diferentemente da narrativa anterior, para a singularidade do $\left|e_{0}\right|$ o desamparo é a sua principal referência semântica, tendo em vista que a protagonista se apresenta em falta de atributos e recursos que lhe permitam enfrentar um mundo que se lhe opõe, assim como a presença de antagonistas e a completa falta de referência a coadjuvantes. Ao contrário de (N1), a protagonista/narradora não é sujeito das ações que narra, mas objeto na ação de outro e, na sequência dos nexos entre os eventos, as circunstâncias é que precedem as escolhas. Por fim, o conteúdo valorativo negativizante das cláusulas narrativas produz sobre o relato um clima moral de desculpa e afastamento.

Com respeito ao clima moral deste relato, é preciso considerar que a situação de rua e de prostituição poderia implicar culpa, desde o ponto de vista de uma audiência virtual. Esta hipótese é antecipada e anulada pela teoria explicativa implícita na narrativa, que enfatiza as circunstâncias que produziram a situação. Embora não se identifiquem cláusulas de avaliação externa, muitos verbos usados fazem parte do campo semântico do desamparo e da vitimização - dada, abandonada, expulsa, humilhada.

A figura narrativa dominante se delineia como hipótese do abandono. De fato, a situação atual, em que acaba o relato, adquire o estatuto de um cenário ao qual a narradora parece ter sido levada à revelia, tendo sido colocada em posição de ter de assumir o ônus de escolhas alheias à sua vontade, como o desfecho de um processo inexorável. A organização retórica da narrativa corrobora essa hipótese.

Em primeiro lugar, a repetição de motivos (abandono), as idas e vindas, de um lugar a outro, sugere a errância da protagonista. Tal expediente estilístico se intensifica à medida que a repetição se particulariza em epanalepse, isto é, a repetição dos mesmos vocábulos em pontos diferentes do texto, próximos uns dos outros ("na casa de um... na casa de outro", e em seguida "ai era humilhada na casa de um... na casa de outro..."). A mesma repetição ainda produz outro efeito estilístico, a paradiástole, pois os seguimentos que se repetem, alinhados, têm igual estrutura sintática, rítmica, iguais extensão e o seu efeito é fortemente afetivo. Todos esses recursos compõem a dramaticidade desse momento em que a protagonista sofre as consequências do abandono, ao passo que devem comover a audiência e conseguir a sua aquiescência. Mais uma vez, essas consequências podem ser remetidas de volta à ação de sua mãe se se considerar a gradação secundária que a narradora ainda produz, a saber, abandonada $\rightarrow$ humilhada $\rightarrow$ expulsa $\rightarrow$ prostituída. Assim, o abandono é a fatalidade que explica sua condição presente, e não há tensão entre circunstâncias e escolha.

\section{Análise de Posicionamento: Nivel 2}

Em (N1), levando-se em consideração a teoria causal implícita na narrativa, o self-ator é discursivamente produzido como culpado, isto é, por ter ido para a rua. É preciso lembrar o resultado da negociação de sentido para a situação de pesquisa (entre o pesquisador e os outros participantes) para medir o alcance dessa construção. Ao mesmo tempo, as suposições acerca de como o self-ator seria recebido pela audiência fazem com que o self-autor, antecipando algum repúdio, tente resguardar o seu protagonista, disfarçando e amenizando a culpa que ele mesmo denuncia, com insinuações que a convertem parcialmente em enredamento. Isso resulta, finalmente, num anti-self envergonhado, vítima de um Mundo sedutor e aprisionador. O self-autor responde ainda ao compromisso com o objetivo de produzir a desculpa e um auxílio para seu protagonista - self-interessado. Acrescenta, então, mais um atributo a ele (carência) e a seu Mundo (possibilidade de redenção). Com isso, produz discursivamente um Outro compassivo, convencido da culpa, também do enredamento, vergonha e carência, para tornar-se oportunidade.

Em (N2), o self-autor torna seus antagonistas responsáveis por circunstâncias que levaram o self-ator, inevitavelmente, à condição degradada em que se encontra, produzindo ao mesmo tempo um self-ator vitimizado e abandonado, e um anti-self desculpado em um Mundo violento. Assim, o self-interessado se satisfaz com a comoção do Outro, de quem solicita além da ajuda a aquiescência aos efeitos morais de sua teoria, a saber, a não-responsabilidade por sua situação presente.

O pesquisador e os protagonistas/narradores são posicionados no aqui e agora dessa situação como o veículo para alcançar outras audiências e os portadores das histórias, respectivamente. Na mesma situação, os acordos parecem avocar, para cada um dos narradores, a tonalidade singular que particulariza sua própria compreensão de si mesmos. O pesquisador é solicitado, diante da (N1), a assumir o compromisso com a culpa, vergonha e carência do protagonista/narrador. Diante da (N2), o pesquisador é solicitado a assumir o compromisso com a desculpa e aquiescência à protagonista/narradora. A Tabela 1 sumariza informações sobre características e caracteres presentes em cada narrativa analisada. 
Matias, H. J. D. (2013). Sedução e Descaminho - Narrativas e Identidades de Jovens em Situação de Rua.

Tabela 1

Comparação entre Características e Caracteres Presentes nas Narrativas

\begin{tabular}{|c|c|c|c|c|c|}
\hline Características & N1 & N2 & Caracteres & $N 1$ & N2 \\
\hline Argumento & enredamento & abandono & Self-autor & $\begin{array}{l}\text { dissimulador } \\
\text { revelador }\end{array}$ & acusador \\
\hline Nexo entre os eventos & $\begin{array}{l}\text { escolha/ } \\
\text { circunstância }\end{array}$ & $\begin{array}{l}\text { circunstâncial } \\
\text { escolha }\end{array}$ & Self-ator & $\begin{array}{l}\text { culpado } \\
\text { carente }\end{array}$ & $\begin{array}{l}\text { vitimizado } \\
\text { abandonado }\end{array}$ \\
\hline Clima moral & $\begin{array}{l}\text { culpa } \\
\text { vergonha }\end{array}$ & $\begin{array}{l}\text { desculpa } \\
\text { afastamento }\end{array}$ & Self-interessado & $\begin{array}{l}\text { desculpa } \\
\text { auxílio }\end{array}$ & $\begin{array}{l}\text { comoção } \\
\text { aquiescência }\end{array}$ \\
\hline \multirow[t]{3}{*}{ Figuras } & $\begin{array}{l}\text { gradação } \\
\text { antítese } \\
\text { insinuação } \\
\text { símbolo } \\
\text { personificação }\end{array}$ & $\begin{array}{l}\text { repetição } \\
\text { epanalepse } \\
\text { paradiástole } \\
\text { gradação }\end{array}$ & Anti-self & envergonhado & desculpado \\
\hline & & & Mundo & $\begin{array}{l}\text { violência } \\
\text { redenção }\end{array}$ & violência \\
\hline & & & Outro & compassivo & compassivo \\
\hline
\end{tabular}

Análise de Posicionamento: Nível 3

É preciso notar a estreita ligação entre o resultado das análises até aqui e a dialética entre casa e rua, assim como o discurso social que opõe estes dois espaços e imprime fortes marcas no modo como a existência desses jovens é por eles mesmos significada. Casa e rua, além de simples espaços, são construídas discursivamente como duas conjunturas que não somente se opõem, mas opõem, pela força de suas determinações, condições bem diversas de existência. Por conseguinte, a passagem da casa à rua $\left(\left|\mathrm{e}_{0}\right|\right)$ se realiza como descontinuidade pejada de sentidos, verdadeira quebra biográfica (Lucchini, 2001), uma ruptura dolorosa comum nas narrativas de jovens em situação de rua (Butler, 2009). O compromisso argumentativo revela que não somente o sair para a rua, mas ficar, permanecer $\mathrm{e}$, de certo modo, pertencer à rua consiste em algo a ser explicado e esclarecido.

A comparação entre as duas narrativas mostra dois modos muito distintos de construir significados para a identidade: uma em que o jovem se apreende como responsável pela construção da própria biografia, outra em que se apreende como vítima de um processo maior que ele mesmo. A primeira posição quanto à própria biografia se mostra compatível com a fala espontânea acerca de projetos de deixar a situação de rua, não somente no relato aqui apresentado, mas também em outros. Por outro lado, a segunda posição se mostra compatível com uma espécie de alheamento concernente ao seu próprio papel na configuração biográfica, ao que se acrescenta a falta de menção ao futuro. Essas configurações, e o contexto em que surgem, dividem também as outras narrativas estudadas (Matias, 2008), de modo que se revelam configurações típicas. Ainda que diante de dois tipos de narrativa, é preciso pontuar que todas se encontram num mesmo contexto de rejeição, privação e violência.

A despeito das diferenças, alguma medida de apagamento do narrador/protagonista na qualidade de sujeito e de agente é norma entre os seus relatos, como aponta Berman (2000), para quem isso implica, na verdade, uma tipologia de identidade e não de narrativas. O autor argumenta que a falta de reflexividade, autoimplicação e de mais complexidade na avaliação de sua própria situação e história podem ser interpretadas como uma estratégia de evitação de percepções e recordações excessivamente angustiantes. Contudo, o compromisso demonstrado com a teoria explicativa é índice justamente da reflexividade desses jovens.

Sanderson e McKeough (2005) sugerem diferenças de gênero que parecem confirmar os resultados obtidos aqui, a saber, que meninas se apresentam mais frequentemente como vítimas (N2) e meninos se descrevem com maior autoeficácia (por vezes, como vitimizadores), os quais também apresentam interpretações mais desenvolvidas de sua história de vida (N1). De fato, o menino da (N1) parece estar mais avançado em sua "carreira" (Lucchini, 2001) ou em seu "arco de experiência", que Ottaway, King e Erickson (2009) descrevem como consistindo em um relato que geralmente inicia em abuso e ruptura, em seguida, a vida nas ruas, um ponto de crise, a partir do qual a pessoa busca apoio em serviços públicos de proteção. Isso leva à saída gradual da rua em direção a uma vida de independência e segurança autossustentadas. Esse ponto de ruptura, ao que tudo indica, deve estar relacionado com o fato de que a situação de rua representa uma ameaça a toda possibilidade de constituição identitária (Berman, 2000; Boydell, Goering, \& Morrell-Bellai, 2000). Ainda 
conforme Boydell et al. (2000), conceber projeções e expectativas para o futuro se constitui em uma estratégia de enfrentamento de grande valor, já que neste futuro estaria localizada a representação de self preferida pelas pessoas em situação de rua.

\section{Conclusão}

De maneira geral, as narrativas analisadas revelam padrões de construção identitária fortemente ligadas ao discurso social que opõe casa e rua. Não obstante, apresentam formas bastante singulares de agenciamento dos mais diversos signos linguísticos. Por um lado, a ligação ao discurso social mostra a heterogeneidade inerente a ele: o mesmo discurso dá sentido à sedução da rua e à expulsão da casa. Por outro lado, a adesão a esses discursos não elimina a possibilidade de que os meninos se posicionem com mais ou menos responsabilidade, sentimento de autoeficácia, perspectiva de futuro, etc.

Ainda que não sejam pretendidas generalizações, esses padrões narrativos sugerem um esboço de tipologia de narrativas que poderia servir como modelo heurístico para interpretar narrativas em outros estudos com essa população e ainda ser desdobrada de modo a integrar mais variantes narrativas típicas. Trata-se de um modelo de estrutura flexível, pois permitiu o vislumbre da singularidade de posicionamentos nas duas narrativas aqui apresentadas.

$\mathrm{O}$ aprofundamento de uma tipologia como essa ofereceria orientações preciosas a profissionais que trabalhem na intervenção junto a crianças e jovens em situação de rua. Segundo Collins e Barker (2009), a grande valorização da autossuficiência e a relutância em buscar e aceitar ajuda, assim como a sua dificuldade de confiar em outros, por parte dos jovens em situação de rua, estão correlacionadas com sentimentos de mágoa, raiva, sentimentos de terem sido traídos pela família e pela sociedade, tão presentes nas narrativas. No entanto, os mesmos jovens revelam disponibilidade para voltar a confiar em pessoas que eles descrevem com características de acentuada empatia. É preciso que os profissionais que com eles trabalham estejam informados sobre como se estruturam e quais os aspectos mais fundamentais pelos quais suas narrativas biográficas devem ser interpretadas.

Por fim, esse estudo contribui para estabelecer e esclarecer a já conhecida relevância das narrativas de história de vida em pesquisas com essa população, demonstrando a riqueza de informação e complexidade dessas narrativas a despeito de sua aparente simplicidade e das suposições de pobreza cognitiva e linguística sobre a fala desses jovens. Com isso, a fala espontânea desses jovens deve ser mais valorizada no âmbito das pesquisas. Em primeiro lugar, pelo conjunto amplo de vantagens metodológicas. Em segundo lugar, e principalmente, em função do apelo ético de procedimentos como este, isto é, da necessidade de inventar meios para o encontro entre a experiência pessoal e irredutível de estar em situação de rua e o tratamento deste fenômeno no espaço público (Finley \& Diversi, 2010).
Além disso, a mesma prática de estímulo à construção de histórias de vida como formas de apresentação de si oferece aos jovens a possibilidade de engajamento em práticas reflexivas com efeitos importantes sobre a significação de suas condições de existência, como a possibilidade de capturar essa esperança num futuro que comporta a representação de um self alternativo (Boydell et al., 2000). O jovem da primeira narrativa apresentada, por exemplo, se mostrou bastante comovido durante e após a entrevista em que contou sua história. Durante os dias que se seguiram à entrevista, ele dizia que ter contado a sua história o fazia pensar em sua vida, na filha que tinha e que morava na casa de sua mãe - "tenho uma filha de um ano e dois meses (3.0) e eu pretendo: sair da rua...". Alguns dias depois, este jovem deixou aquele grupo de pessoas que participou da pesquisa, e o que as pessoas do grupo diziam sobre ele é que tinha voltado para casa.

\section{Referências}

Alves-Mazzotti, A. J. (1997). Representações sociais de "meninos de rua". Educação e Realidade, 22(1), 183-207.

Alvim, R. (2001). Meninos de rua e criminalidade. In N. Esterci, P. Fry, \& M. Goldenberg (Eds.), Fazendo Antropologia no Brasil (pp. 189-204). Rio de Janeiro, RJ: DP\&A.

Bamberg, M. (2004). Narrative discourse and identities. In J. C. Meister, T. Kindt, W. Schernus, \& M. Stein (Eds.), Narratology beyond literary criticism (pp. 213-237). Berlin, Germany: Walter de Gruyter.

Bamberg, M. (2008). Selves and identities in the making - The study of the microgenic processes in interactive practices. In U. Müller, J. I. M. Carpendale, N. Budwig, \& B. Sokol (Eds.), Social Life and Social Knowledge (pp. 205-224). New York: LEA.

Bamberg, M., \& Georgakopoulou, A. (2008). Small stories as a new perspective in narrative and identity analysis.Text \& Talk, 28, 377-396.

Berman, L. (2000). Surviving on the Streets of Java: Homeless Children's Narratives of Violence. Discourse Society, 11(2), 149-174.

Boydell, K. M., Goering, P., \& Morrell-Bellai, T. L. (2000). Narratives of identity: Re-presentarion o self in people who are homeless. Qualitative Helth Research, 10(1), 26-38.

Brunanski, D. (2008). Interventions with Aboriginal street youth in Western Canada: A narrative exploration of experiences withcounseling. International Journal of Psychology, 43(34), 69-69.

Bruner, J. (1996). A narrative model of self construction. Psyke \& Logos, 17(1), 154-170.

Bruner, J. (1997). Atos de significação. Porto Alegre, RS: Artes Médicas.

Bruner, J. (1998). Realidade mental, mundos possiveis. Porto Alegre, RS: Artes Médicas.

Bucholtz, M., \& Hall, K. (2005). Identity and interaction: a sociocultural linguistic approach. Discourse Studies, 7(4-5), 585-614.

Butler, U. M. (2009). Freedom, revolt and 'citzenchip' - Three pillars of identity of youngsters living on the streets of Rio de Janeiro. Childhood, 16(1), 11-29.

Collins, P., \& Barker, C. (2009). Psychological help-seeking in homeless adolescents. International Journal of Social Psychiatry, 55, 372-384. 
Matias, H. J. D. (2013). Sedução e Descaminho - Narrativas e Identidades de Jovens em Situação de Rua.

Cruz, M. N. A., \& Assunção, A. A. (2008). Estrutura e organização do trabalho infantil em situação de rua em Belo Horizonte, MG, Brasil. Saúde e Sociedade, 17(1),131-142.

Ezzy, D. (1998). Theorizing narrative identity: symbolic interactionism and hermeneutics. The Sociological Quarterly, 39(2), 239-252.

Finley, S., \& Diversi, M. (2010). Critical Homelessness: expanding narratives of inclusive democracy. Cultural Studies - Critical Methodologies, 10, 4-13.

Georgakopoulou, A. (2006). The other side of story: Towards a narrative analysis of narratives-in-interaction. Discoursive Studies, 8(2), 235-257.

Gregori, M. F. (2000). Viração: Experiências de meninos de rua. São Paulo, SP: Companhia das Letras.

Grundling, J., \& Grundling, I. (2005). The concrete particulars of the everyday realities of street children. Human Relations, 58(2), 173-190.

Guareschi, N. M. F., Oliveira, F. P., Giannechini, L. G., Communello, L. N., Nardini, M., \& Pacheco, M. L. (2002). A rua, a casa e a escola: A construção de identidade de meninos e meninas. Estudos e Pesquisas em Psicologia, 2(2), 91-107.

Habermas, J. (1990). Pensamento pós-metafísico. Estudos filosóficos. Rio de Janeiro, RJ: Tempo Brasileiro.

Haldenby, A. M., Berman, H., \& Forchuk, C. (2007). Homelessness and Health in Adolescents. Qualitative Health Research, 17(9), 1232-1244.

Hodgetts, D., Hodgetts, A., \& Radley, A. (2006). Life in the shadow of the media: Imaging street homelessness in London. European Journal of Cultural Studies, 9, 497-516.

Invernizzi, A. (2003). Street-Working Children and Adolescents in Lima: Work as an Agent of Socialization. Childhood, 10(3), 319-341.

Jones, K. (2003). The turn to a narrative knowing of persons: One method explored. Narrative Studies, 8(1), 60-71.

Labov, W. (1972). The transformation of experience in narrative syntax. In W. Labov (Ed.), Language in the inner city: Studies in Black English vernacular (pp. 354-396). Philadelphia, PA: University of Philadelphia Press.

Labov, W. (1997). Some further steps in narrative analysis. The Journal of Narrative and Life History, 7, 395-415.

Lucchini, R. (2001). Carrière, identité et sortie de la rue: la cas de l'enfant de la rue. Déviance et Société, 25(1), 75-97.

Mathur, M. (2009). Socialization of street children in India: A socio-economic profile. Psychology Developing Societies, 21(2), 299-325.

Matias, H. J. D. (2008). Identidade, espaço e tempo: Negociações de sentido sobre a 'gente de rua' (Dissertação de mestrado, Departamento de Psicologia, Universidade Federal do Rio Grande do Norte, Natal, RN, Brasil).

Matias, H. J. D. (2011). Jovens em situação de rua: Espaço, tempo, negociações de sentido. Psicologia \& Sociedade, 23(2), 237-247.

Matias, H. J. D., \& Francischini, R. (2010a). Crianças em situação de rua: Trabalho e processos de socialização. In: N. A. Morais, L. Neiva-Silva, \& S. H. Koller (Eds.), Endereço desconhecido - Crianças e adolescentes em situação de rua (pp. 263-293). São Paulo, SP: Casa do Psicólogo.

Matias, H. J. D., \& Francischini, R. (2010b). Desafios da etnografia com jovens em situação de rua: A entrada em campo. Psicologia: Reflexão \& Crítica, 23(2), 243-252.

Mattos, R. M., \& Ferreira, R. F. (2004). Quem vocês pensam que (elas) são? - Representações sobre pessoas em situação de rua. Psicologia \& Sociedade, 16(2), 47-58.
Mead, G. H. (1972). Espiritu, persona y sociedad. Buenos Aires, Argentina: Paidós. (Original publicado em 1934)

Nóbrega, S. M., \& Lucena, T. A. (2004). O "menino de rua" entre o sombrio e a aberrância da exclusão social. Estudos de Psicologia (Campinas), 21(3), 161-172.

Ochs, E., \& Capps, L. (1996). Narratingthe self. Annual Review of Anthropology, 25, 19-43.

Ottaway, N., King, K., \& Erickson, P. G. (2009). Storying the street: Transition narratives of homeless youth. Medical Humanities, 35(1), 19-26.

Raffaelli, M., Koller, S. H., Reppold, C. T., Kuschick, M. B., Krum, F. M. B., \& Bandeira, D. (2001). How do Brazilian street youth experience 'The Street'?: Analysis of a sentence completion. Childhood, 8(3), 396-415.

Ribeiro, M. O. (2003). A rua: Um acolhimento falaz às crianças que nela vivem. Revista Latino-Americana de Enfermagem, 11(5), 622-629.

Rio, J. (2008). A alma encantadora das ruas. São Paulo, SP: Companhia das Letras. (Original publicado em 1908)

Rosa, M. D. (1999). O discurso e o laço social dos meninos de rua. Psicologia USP, 10(2), 205-217.

Sanderson, A., \& McKeough, A. (2005). A narrative analysis of behaviourally troubled adolescents' life stories. Narrative Inquiry, 15(1), 127-160.

Trussell, R. P. (1999). The children's streets: An ethnographic study of street children in Ciudad Juárez, Mexico. International Social Work, 42(2), 189-199.

Vogel, A., \& Mello, M. A. S. (1996). Da casa à rua: A cidade como fascínio e descaminho. In A. Fausto \& R. Cervini (Eds.), O Trabalho e a Rua: Crianças e adolescentes no Brasil dos anos 80 (pp. 133-150). São Paulo, SP: Cortez. 